\title{
Long-term Effect of Transurethral Resection of Bladder Tumour Combined with Intravesical Instillation of Pirarubicin on Immune Function in Superficial Bladder Cancer
}

\author{
R. FENG* \\ Department of Urology, Linzi District People's Hospital, Zibo City, P. R. China
}

\author{
Feng: Long-Term Effect of TURBT on Superficial Bladder Cancer
}

\begin{abstract}
This study was aimed to explore the long-term effects of transurethral resection of bladder tumour combined with intravesical instillation of pirarubicin on immune function in superficial bladder cancer. Eighty four patients with bladder cancer admitted to the Linzi District People's Hospital from March 2016 to March 2017 were selected as research subjects and divided into 2 groups according to the digital table. The control group was treated with transurethral resection of bladder tumour. The study group was given intravesical instillation of pirarubicin in addition to the treatment given to the control group. There was no significant difference in recurrence rate between the study group and the control group, 6 mo after operation. However, the recurrence rate in the study group was lower than that in the control group $1 \mathrm{y}$ after operation and the recurrence time of the study group was significantly shorter than that of the control group. There was no significant difference in the incidence of postoperative complications between the study group and the control group and the levels of IgM, IgG and IgA in the study group were significantly higher than those in the control group. In addition the levels of $\mathrm{CD}^{4+}, \mathrm{CD}^{4+} / \mathrm{CD}^{8+}$ in the study group were significantly higher than those in the control group, while the $\mathrm{CD}^{8+}$ in the study group was significantly lower than that in the control group. In conclusion, transurethral resection of bladder tumour combined with intravesical instillation of pirarubicin is effective in the treatment of bladder cancer and should be further popularized in clinic.
\end{abstract}

Key words: Transurethral resection of bladder tumour, pirarubicin, bladder perfusion, long-term effect, immune function

Bladder tumour is a common disease in urology which ranks as the $17^{\text {th }}$ and $7^{\text {th }}$ most common tumours in women and men, respectively ${ }^{[1]}$. More than $70 \%$ of bladder tumours are noninvasive or superficially invasive at diagnosis. Transurethral resection of bladder tumour (TURBT) is the preferred treatment for these patients, but it usually leads to recurrence of tumours, so more active treatments are required ${ }^{[2]}$. Intravesical therapy may be another treatment for superficial bladder cancer. In the course of treatment, drugs are injected directly into the bladder through a catheter. It ensures high concentrations of drugs in bladder tissue, while reducing systemic exposure and adverse reactions. Immunotherapeutic and chemotherapeutic drugs are the most common drugs for intravesical use of bladder cancer ${ }^{[3]}$. The commonly used drugs in clinical practice include pirarubicin and doxorubicin. Pirarubicin, an analogue of adriamycin containing tetrahydro pyrrolidone, which can enhance its anticancer ability.
Pirarubicin prevents DNA replication and transcription in cancer cells, therefore, cancer cells are prevented from dividing, thereby reducing the risk of recurrence ${ }^{[4]}$. In this study, the long-term effects of TURBT combined with intravesical instillation of pirarubicin were explored on immune function in patients with bladder cancer in order to provide a basis for clinical practice.

Eighty four patients with bladder cancer admitted to the Linzi District People's Hospital from March 2016 to March 2017 were enrolled and divided into 2 groups according to the digital table method, with 42 cases in each group. The control group consisted of 28 males and 14 females with an average age of $58.3 \pm 2.3$ y. Tumor stages ${ }^{[5]}$ of the 42 cases are as follows, 24 cases in Ta stage and 18 cases in T1 stage. There were 27 males and 15 females in the study group, with an average age of $57.5 \pm 3.1 \mathrm{y}$. Tumour stages are, 25 cases in Ta stage and 17 cases in T1 stage. There was no significant difference between the 2 groups in 
terms of age, gender and tumour stage, as shown in Table 1. The patients in this study were informed about participating in the study before signing the consent form, which was approved by the Hospital Ethics Committee. Inclusion criteria were, patients diagnosed with superficial bladder cancer after clinical diagnosis; patients with no liver and kidney dysfunction, and patients with high postoperative compliance to complete subsequent treatment and follow-up. Exclusion criteria were, patients with severe urinary infection; patients who are intolerant to drugs in this study and patients who are not willing to participate in this study.

The control group was subjected to TURBT. The specific procedure is as follows, the patient underwent epidural anaesthesia and took the lithotomy position. After confirming the success of anaesthesia, the Wolf resectoscope was placed through the urethra to confirm the location of bladder tumours. For patients with small basal tumours, the electrosurgical parameters were set to $60 \mathrm{~J}$ electrocoagulation power and $100 \mathrm{~J}$ electric power. For patients with large basal tumours, the tissue covering the tumour pedicle was removed first, and then the tumour was completely removed. Then, $2 \mathrm{~cm}$ of tissue was burnt around the tumour pedicle to prevent postoperative recurrence ${ }^{[6]}$. Patients in the study group were given intravesical instillation of pirarubicin in addition to the treatment received by the control group. Specific details are as follows, the operation method was the same as that of the control group. After the operation, $30 \mathrm{mg}$ pirarubicin was dissolved in $50 \mathrm{ml}$ sterilized water for perfusion (Chinese medicine quasi character H10930105, Shenzhen Wan Le Pharmaceutical Co., Ltd). The first perfusion was performed on $\mathrm{d} 2$ after operation, and once a week for $8 \mathrm{w}$. Then the perfusion period was adjusted to once a month for $1 \mathrm{y}^{[7]}$.

The postoperative recurrence rate was recorded in the 2 groups 6 mo and $1 \mathrm{y}$ after operation in the followup. The incidence of postoperative complications in the 2 groups was statistically analysed, including

TABLE 1: COMPARISON OF GENERAL CHARACTERISTICS BETWEEN THE 2 GROUPS

\begin{tabular}{lcccccc}
\hline \multirow{2}{*}{ Groups } & \multicolumn{3}{c}{ Nender } & & \multicolumn{2}{c}{ Tumor stage } \\
\cline { 3 - 4 } & & Male Female & Age & $\begin{array}{c}\text { Ta } \\
\text { stage }\end{array}$ & $\begin{array}{c}\mathrm{T} 1 \\
\text { stage }\end{array}$ \\
\hline Control group & 42 & 28 & 14 & $58.3 \pm 2.3$ & 24 & 18 \\
Study group & 42 & 27 & 15 & $57.5 \pm 3.1$ & 25 & 17 \\
$\mathrm{X}^{2} / \mathrm{t}$ & $/$ & 0.053 & 0.342 & 0.049 \\
$\mathrm{P}$ & $/$ & $>0.05$ & & $>0.05$ & $>0.05$ \\
\hline
\end{tabular}

myelosuppression, ureteral injury, bladder perforation and urinary irritation symptoms. The levels of serum $\operatorname{IgM}$, IgG and IgA, which represent the humoral immunity, were measured using the enzyme-linked immunosorbent assay in both groups. Flow cytometry was used to detect and analyse $\mathrm{CD}^{4+}, \mathrm{CD}^{8+}$ as well as the ratio of $\mathrm{CD}^{4+} / \mathrm{CD}^{8+}$, which represent the cellular immunity in the 2 groups.

The data was analysed using SPSS 18.0, in which the count data was subjected to Chi-square test (\%), while the measurement data was subjected to $t$ test $(\mathrm{x} \pm \mathrm{s}) . \mathrm{p}<0.05$ indicated significant difference. There was no significant difference in the recurrence rate between the study group and the control group 6 mo after operation, as shown in Table 2. There was no difference in the incidence of complications, including myelosuppression, ureteral injury, bladder perforation, urinary irritation symptoms and total rate, between the study group and the control group, as shown in Table 3. The levels of IgM, IgG and IgA in the humoral immunity of the study group were higher than those of the control group, as shown in Table 4.

The levels of $\mathrm{CD}^{4+}, \mathrm{CD}^{4+} / \mathrm{CD}^{8+}$ in the cellular immunity of the study group were significantly higher than those of the control group, while the $\mathrm{CD}^{8+}$ in the cellular immunity of the study group was significantly lower than that of the control group, as depicted in Table 5. Bladder cancer is a malignant tumour, which has a serious impact on people's quality of life, mainly including superficial bladder cancer ${ }^{[8]}$. At present, TURBT is the main treatment for this disease, but it has a relatively high recurrence rate in clinical practice, which seriously limits its therapeutic utility ${ }^{[9]}$. Although some therapeutic strategies such as systemic immunotherapy/chemotherapy and radiotherapy have been adopted recently, the overall survival rate has not improved and the incidence and even mortality of bladder cancer are very high. Therefore, it is clear that alternative treatment for bladder cancer is still needed ${ }^{[10]}$. Researchers have found that postoperative intravesical instillation can effectively improve the treatment outcome and reduce the recurrence rate ${ }^{[11,12]}$. The drugs

\section{TABLE 2: COMPARISON OF RECURRENCE RATE BETWEEN THE 2 GROUPS}

\begin{tabular}{lccc}
\hline \multirow{2}{*}{ Groups } & \multirow{2}{*}{ N } & \multicolumn{2}{c}{ Recurrence after operation } \\
\cline { 3 - 4 } & & $6 \mathrm{mo}$ & $\mathbf{1} \mathrm{y}$ \\
\hline Control group & 42 & $2(4.8 \%)$ & $8(19.0 \%)$ \\
Study group & 42 & $1(2.4 \%)$ & $2(4.8 \%)$ \\
$\mathrm{X}^{2}$ & $/$ & 0.346 & 4.086 \\
$\mathrm{P}$ & $/$ & $>0.05$ & $<0.05$ \\
\hline
\end{tabular}


TABLE 3: COMPARISON OF POSTOPERATIVE COMPLICATIONS BETWEEN THE 2 GROUPS

\begin{tabular}{lcccccc}
\hline Groups & N & Myelosuppression & Ureteral injury & $\begin{array}{c}\text { Bladder } \\
\text { perforation }\end{array}$ & $\begin{array}{c}\text { Urinary irritation } \\
\text { symptoms }\end{array}$ & Total rate \\
\hline Control group & 42 & $0(0.0)$ & $2(4.8)$ & $1(2.4)$ & $1(2.4)$ & $4(9.5)$ \\
Study group & 42 & $2(4.8)$ & $1(2.4)$ & $0(0.0)$ & $1(2.4)$ & $4(9.5)$ \\
$X^{2}$ & $/$ & 2.049 & 0.346 & 1.012 & 0 & 0 \\
P & I & $>0.05$ & $>0.05$ & $>0.05$ & $>0.05$ & $>0.05$ \\
\hline
\end{tabular}

TABLE 4: COMPARISON OF HUMORAL IMMUNITY BETWEEN THE 2 GROUPS

\begin{tabular}{lccccc}
\hline Groups & $\mathrm{N}$ & Time & $\operatorname{lgM}(\mathrm{g} / \mathrm{l})$ & $\operatorname{lgG}(\mathrm{g} / \mathrm{l})$ & $\mathrm{IgA}(\mathrm{g} / \mathrm{l})$ \\
\hline Control group & 42 & Before treatment & $0.3 \pm 0.1$ & $3.1 \pm 1.5$ & $0.2 \pm 0.1$ \\
& & After treatment & $0.8 \pm 0.2^{\mathrm{a}}$ & $10.4 \pm 1.5^{\mathrm{a}}$ & $0.9 \pm 0.2^{\mathrm{a}}$ \\
Study group & 42 & Before treatment & $0.3 \pm 0.2$ & $3.1 \pm 1.5$ & $0.2 \pm 0.1$ \\
& & After treatment & $1.9 \pm 0.7^{\mathrm{ab}}$ & $13.7 \pm 3.9^{\mathrm{ab}}$ & $1.7 \pm 0.9^{\mathrm{ab}}$ \\
\hline
\end{tabular}

${ }^{a} p<0.05$ vs. before treatment, ${ }^{b} p<0.05$ vs. after treatment in the control group

TABLE 5: COMPARISON OF CELLULAR IMMUNITY BETWEEN THE 2 GROUPS

\begin{tabular}{lccccc}
\hline Groups & $\mathrm{N}$ & Time & $\mathrm{CD}^{4+}(\%)$ & $\mathrm{CD}^{8+}(\%)$ & $\mathrm{CD}^{4+} / \mathrm{CD}^{8+}(\%)$ \\
\hline Control group & 42 & Before treatment & $12.3 \pm 5.3$ & $8.3 \pm 2.3$ & $1.5 \pm 0.2$ \\
& & After treatment & $36.7 \pm 4.3^{\mathrm{a}}$ & $17.4 \pm 2.9^{\mathrm{a}}$ & $2.1 \pm 0.6^{\mathrm{a}}$ \\
Study group & 42 & Before treatment & $12.3 \pm 5.3$ & $8.3 \pm 2.1$ & $1.5 \pm 0.3$ \\
& & After treatment & $40.1 \pm 3.2^{\mathrm{ab}}$ & $14.3 \pm 3.5^{\mathrm{ab}}$ & $2.7 \pm 0.5^{\mathrm{ab}}$ \\
\hline
\end{tabular}

${ }^{a} \mathrm{p}<0.05$ vs. before treatment, ${ }^{b} \mathrm{p}<0.05$ vs. after treatment in the control group

for bladder perfusion are mainly divided into biological agents and chemotherapeutic drugs. However, the side effects of biological agents in the clinical application are very large ${ }^{[13]}$. Therefore, chemotherapeutic drugs have become the main drugs for bladder perfusion. Currently, the commonly used drugs in clinical practice include pirarubicin and doxorubicin ${ }^{[14]}$. Pirarubicin can prevent DNA replication and transcription in cancer cells, thus, cancer cells are prevented from dividing, thereby reducing the risk of recurrence ${ }^{[4]}$.

In this study, pirarubicin perfusion was given to patients treated with TRUBT. Subsequently, it was found that the recurrence rate of the study group was lower than that of the control group, and it did not increase the incidence of postoperative complications. In addition, the immune status of patients was also compared between the study group and the control group and the results revealed that immune status of the study group was better than that of the control group. In summary, in the treatment of bladder cancer, TURBT combined with pirarubicin bladder infusion can effectively reduce the recurrence rate and improve patient's immune status, which should be further promoted and applied clinically.

\section{Conflict of interest:}

No conflict of interest between any of the authors.

\section{REFERENCES}

1. Chen HR, Kao CC, Tsao CW, Tang SH, En M, Cha TL, et al. Comparison of Different Treatment Schedules of Mitomycin C Intravesical Instillation in High-Risk Superficial Bladder Cancer Patients. Aktuelle Urol 2019;50:292-7.

2. Mattioli F, Curotto A, Manfredi V, Gosmar M, Garbero C, Ambruosi $\mathrm{C}$, et al. Intravesical gemcitabine in superficial bladder cancer: a phase II safety, efficacy and pharmacokinetic study. Anticancer Res 2005;25:2493-6.

3. Cozzi PJ, Bajorin DF, Tong W, Nguyen H, Scott J, Heston WD, et al. Toxicology and pharmacokinetics of intravesical gemcitabine: a preclinical study in dogs. Clin Cancer Res 1999;5:2629-37.

4. Okamura K, Ono Y, Kinukawa T, Matsuura O, Yamada S, Ando T, et al. Randomized study of single early instillation of (2r)-4-o-tetrahydropyranyl-doxorubicin for a single superficial bladder carcinoma. Cancer 2002;94:2363-8.

5. Sun Y, Guan Z, Liang L, Cheng Y, Zhou J, Li J, et al. NF$\kappa \mathrm{B}$ signaling plays irreplaceable roles in cisplatin-induced bladder cancer chemo resistance and tumor progression. Int $\mathrm{J}$ Oncol 2016;48:225-34.

6. Dingyi C, Honglin H, Xiaoqing X. Effect of surgery combined with chemotherapy on peripheral blood $\mathrm{CD}^{4+} \mathrm{CD}^{25+} \mathrm{CD} 127$ low/Treg count in patients with bladder cancer. Shandong Med 2016;56:45-6.

7. Tao H, Yan W, Wei Z, Yu Z, Transurethral resection surgery in treatment of superficial bladder cancer with benign prostate hyperplasia. J Third Mil Med Univ 2016;38:1729-34.

8. Vandeveer AJ, Schlom J, Greiner JW. Systemic immunotherapeutic efficacy of an immunocytokine, NHSmuIL12, in a superficial murine orthotopic bladder cancer model. Cancer Res 2016;7:1480.

9. Ismail MF, El Boghdady NA, Shabayek MI, Awida HA, Abozeed H. Evaluation and screening of mRNA S100A genes 
as serological biomarkers in different stages of bladder cancer in Egypt. Tumor Biol 2016;37:4621-31.

10. Shimizu H, Akasaka S, Suzuki S, Akimoto M, Shimada $\mathrm{T}$. Preferential gene transfer to $\mathrm{BBN}$-induced rat bladder tumor by simple instillation of adenoviral vector. Urology 2001;57:579-84.

11. Shujun Z, Gengze W, Jianwen L. Clinical observation of 5-Fluorouracil-based chemotherapy combined with threedimensional conformal intensity modulated radiotherapy for advanced gastric cancer. China Pharmacy 2016;27:2062-4.

12. Pietzak EJ, Bagrodia A, Cha EK, Drill EN, Iyer G, Isharwal $\mathrm{S}$, et al. Next-generation sequencing of non-muscle invasive bladder cancer reveals potential biomarkers and rational therapeutic targets. European Urol 2017;72:952-9.

13. Zhao C, Tang K, Yang H, Xia D, Chen Z. Bipolar versus monopolar transurethral resection of nonmuscle-invasive bladder cancer: a meta-analysis. J Endourol 2016;30:5-12.

14. Shibao F, Xixi F, Shuming H. Comparison of clinical effects of different urinary diversion schemes after minimally invasive resection of bladder cancer. J Endos C 2017;23:66-70.

This is an open access article distributed under the terms of the Creative Commons Attribution-NonCommercial-ShareAlike 3.0 License, which allows others to remix, tweak, and build upon the work non-commercially, as long as the author is credited and the new creations are licensed under the identical terms

This article was originally published in a special issue, "XXXXXX"

Indian J Pharm Sci 2020:82(1)spl issue1; XX-XX 